\title{
INVERSION OF EXTENDED ELASTIC IMPEDANCE FOR TRANSITIONAL ENVIRONIMENT INTERPRETATION: APPLIED TO THE CRETACEOUS GACHETÁ FORMATION IN THE LLANOS BASIN - COLOMBIA
}

\author{
Diego Alberto Melo Guarin, Luis Hernán Ochoa Gutierrez and Luis Alfredo Montes Vides
}

\begin{abstract}
The Extended Elastic Impedance (EEI) is a generalization of the acoustic impedance (Al) to non-zero incidence angles $\theta$ allowing the inversion of sections created by the weighted combinations of intercept and gradient to discriminate fluids and lithology. For certain angle $\chi$, related to $\theta$ by $\sin ^{2} \theta=\tan \chi$, the EEl at that angle is proportional to some elastic parameter such as of Lamés, the Bulk module and the $V_{p} / V_{s}$ ratio. The technique is fruitful in offshore projects, where seismic data are generally of good quality. The Llanos basin in Colombia contains rocks of the Cretaceous transitional with stratigraphic traps of hydrocarbon deposits. The EEI inversion quantified parameters that together allowed the interpretation of lateral changes in lithology and the definition of sand channels of the transitional environment in lithic units of the Cretaceous Gachetá Formation, in an onshore seismic project in the Llanos basin in Colombia.
\end{abstract}

Keywords: inversion, onshore seismic, stratigraphy.

RESUMO. A Impedância Elástica Estendida (em inglês, Extended Elastic Impedance - EEI) é a generalização da impedância acústica (Al) para ângulos de incidência não-zero $\theta$ permitindo a inversão de seç̃̃es criadas pelas combinações ponderadas de intercepção e gradiente para discriminar fluidos e litologia. Para certo ângulo $\chi$, relacionado a $\theta$ por $\operatorname{sen}^{2}=\tan \chi$, a EEl nesse ângulo é proporcional a algum parâmetro elástico, como os de Lamé, o módulo Bulk e a relação $V_{p} / V_{s}$. A técnica é frutífera em projetos no mar, onde os dados sísmicos são geralmente de boa qualidade. A bacia de Llanos na Colômbia contém rochas de ambientes de transição do período Cretáceo com armadilhas estratigráficas de depósitos de hidrocarbonetos. Os parâmetros conjuntamente quantificados por inversão da EEl, permitiram a interpretação de mudanças laterais em litologia e a definição de canais de areia do ambiente de transição em unidades rochosas da Cretácica Formação Gachetá, em um projeto sísmico terrestre na bacia de Llanos na Colômbia.

Palavras-chave: inversão, sísmica terrestre, estratigrafia. 


\section{INTRODUCTION}

As known, weighted stacked sections are used to detect the presence of fluids according to with Poisson ratio $\sigma$ sections (Smith \& Gidlow, 1987). Besides, changes observed density $\rho$ sections as well as sections of parameters of Lamé $\mu \rho-\lambda \rho$ have been used to discriminate lithology and fluids (Goodway et al., 1997). On the other hand, variations in density, bulk $\kappa$, and shear $\mu$ modules have been expressed in function of intercept, gradient and curvature sections (Dong, 1996) to enhance AVO response. Under the previous considerations, Connolly (1999) introduced the elastic impedance (IE) which calibrate with borehole data the inversion of stacked sections at reflection angles even at far offset, relating them with some elastic parameters and hence with fluids. The $E E I(\theta)$, normalized and extended to the angle $\chi$, through $\sin ^{2} \theta=\tan \chi$, becomes Extended Elastic Impedance $E E I(\chi)$ which allows the discrimination of lithology (Whitcombe et al., 2002). EEl applies to projects where other inversion techniques did not distinguish the slight change in the acoustic impedance of gas sands involved in shales (Connolly et al., 2002; Hicks \& Francis, 2006; Arsalan \& Yadav, 2009; Awosemo, 2012). These references indicate that the technique is fruitful in offshore projects, where seismic data are generally of good quality. The Llanos basin of Colombia contains deposits of the Cretaceous transitional environment whose lithological lateral changes determine the stratigraphic trap of a hydrocarbon deposit. The EEI inversion of a $3 \mathrm{D}$ onshore project in the Llanos basin provides sections of elastic parameters whose integrated analysis allowed a new interpretation and defined the geometry of sand channels as potential reservoirs.

\section{Extended Elastic Impedance - EEI}

From the Shuey equation (1985) which models the acoustic response of a reflector that separates two media regarding average density and average velocities $\alpha$ and $\beta$ of acoustic and shear waves, Connolly (1999) derives the equation for elastic impedance:

$$
I E(\theta)=\alpha_{o} \rho_{0}\left[\left(\frac{\alpha}{\alpha_{o}}\right)^{a}\left(\frac{\beta}{\beta_{o}}\right)^{b}\left(\frac{\rho}{\rho_{o}}\right)^{c}\right]
$$

where $a=1+\sin ^{2} \theta, b=-8 k \sin ^{2} \theta, c=1-4 k \sin ^{2} \theta$ and $k=(\alpha / \beta)^{2}$ represents the average value along the target interval $y \alpha_{o}, \beta_{o}, \rho_{o}$ are the average values in the same interval. As a result, Eq. (1) supplies normalized impedance values in the interval of interest. The expressions of the AV0 parameters intercept $A$, gradient $B$, and curvature $C$ depend on the changes in the Bulk $\Delta \kappa$ and $\Delta \mu$ shear modules, and variations in density $\Delta \rho$ (Dong, 1996). Expressions that makes possible to estimate the pseudo reflectivity logs associated with these parameters as a function of the three AVO parameters, according to:

$$
\begin{aligned}
& R_{\kappa}=\frac{\Delta \kappa}{2 \kappa}=\left(A+B \frac{1}{3+2 f}\right)\left(\frac{3+2 f}{3-4 k}\right) \\
& R_{\lambda}=\frac{\Delta \lambda}{2 \lambda}=\left(A+B \frac{1}{2+f}\right)\left(\frac{2+f}{2-4 k}\right) \\
& R_{\mu}=\frac{\Delta \mu}{2 \mu}=\left(A-B \frac{1}{f}\right)\left(\frac{f}{4 k}\right)
\end{aligned}
$$

By establishing $f=C / A$ with constant $k$ in the interval of interest, Eqs. (2), (3) and (4) represent the Shuey equation: $A+B \sin ^{2} \theta$ each one multiplied by a different scalar. According to Shuey (1985) $0 \leq f \leq 1$, but in case of $f=0.8$ and $k=0.25$ (rocks that respect the Gardner relation), Eq. (4) supplies the exotic result $\sin ^{2} \theta_{\mu}=-1 / f=-1.255$. The replacement of $A+B \sin ^{2} \theta$ by $A+B \tan \chi$ overcomes the previous situation (Whitcombe et al., 2002) to finally derive the expression for EEl:

$$
\operatorname{EEI}(\chi)=\alpha_{o} \rho_{0}\left[\left(\frac{\alpha}{\alpha_{o}}\right)^{p}\left(\frac{\beta}{\beta_{o}}\right)^{q}\left(\frac{\rho}{\rho_{o}}\right)^{r}\right]
$$

with $p=\cos \chi+\sin \chi, q=-8 k \sin \chi$ and $r=\cos \chi-$ $4 k \sin \chi$.

\section{Geological Setting}

The considered zone is in the Llanos basin - Colombia which contains a 3D cube of $72 \mathrm{~km}^{2}$ restricted to an estimated thickness of 400 feet in the Gachetá Formation of the Upper Cretaceous, in a transitional environment where sand channels deposited constitute deposits of light oil (Fig. 1A). The Llanos basin forms an asymmetric sedimentary wedge typical of a foreland basin, and structurally it is a monocline that dips gently to the east, tilting the entire basin. The main characteristic of the Llanos basin is the presence of mostly normal fault trains with strike components in a direction that varies from N10E to N3OE, associated with small normal antithetical faults, as seen in Figure 1B. The Llanos basin is an interbedding of dark gray, gray and black mudstone with thin glauconitic sandstones and locally with limestones, schists, and siliceous mudstones, where the sand content increases to the northeast being the units thicker to the west. Figure $1 \mathrm{C}$ shows the generalized paleography for the Upper Cretaceous with reactivation of the sediment source area and initiation of a prograding sequence and the subsequent retirement of the sea under delta 

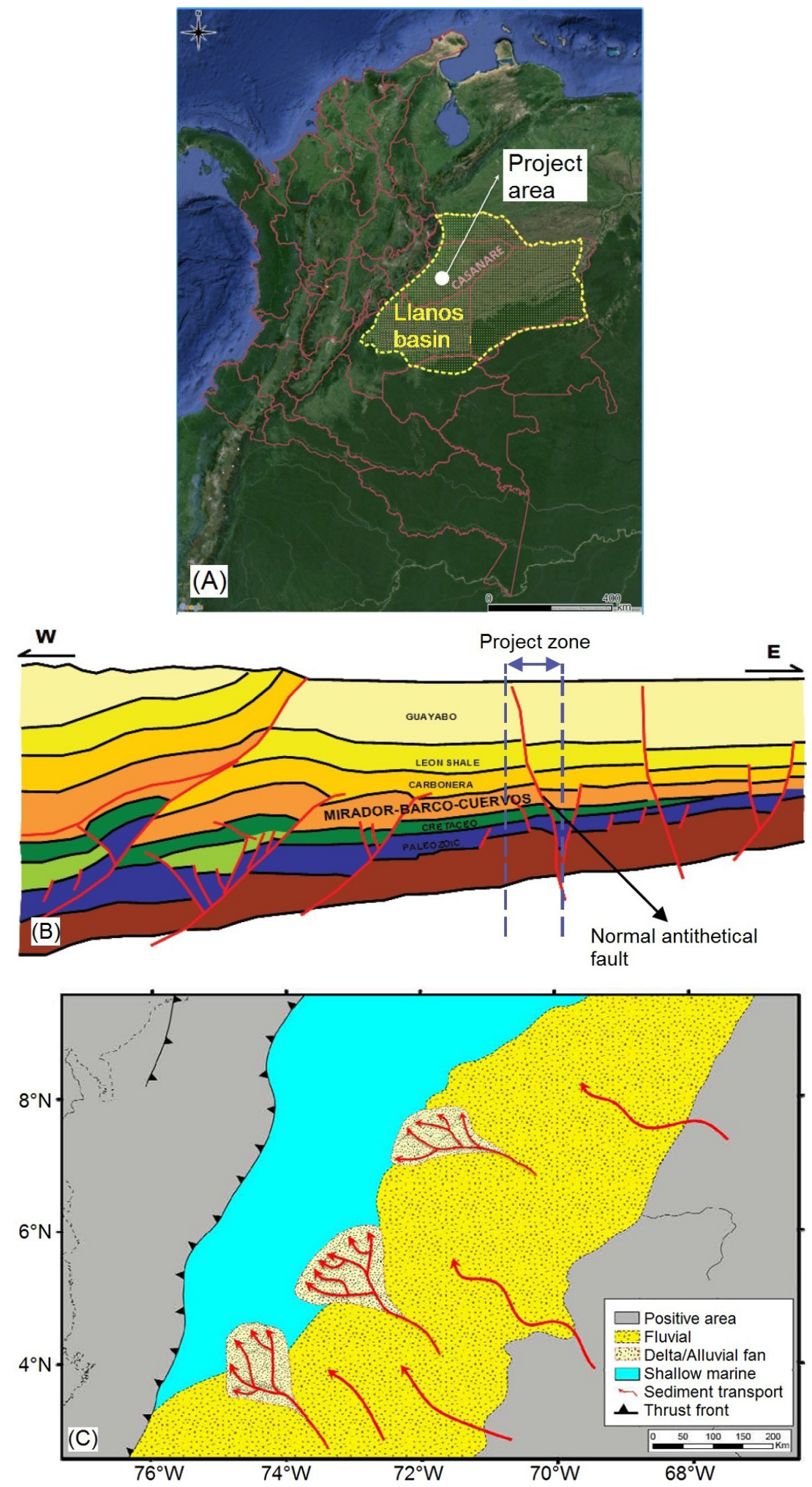

Figure 1 - A) Location of the study area in the central sector of the Llanos basin, Department of Casanare-Colombia. B) Generalized structural scheme of the Llanos basin in the central zone. C) Paleographic map with tectonic reconstruction of the basin during the Late Cretaceous (Campos \& Mann, 2015). 
conditions, although the east of the basin remained as low positive relief (Campos \& Mann, 2015). A stratigraphy sequence achieved by flood surfaces correlation allowed the division of the Gachetá Formation, from top to base, in the G1, G2, G3, G4, and G5 units. Analysis of $11 \mathrm{GR}$ logs shows that the overlying Guadalupe Formation and the underlying Ubaque Formation contain sandstones with lateral continuity, as in the G1 Ubaque unit but with intercalations of thin layers of clay. These sands packs are best observed in some sections of the wells depending on whether they are inside or outside the channel. The Gachetá Formation depth is in the range of 9500 to 10000 feet in the area where the seismic waves have a low-frequency content. The average acoustic velocity is $2700 \mathrm{~m} / \mathrm{s}$, its vertical resolution is $25 \mathrm{~m}$, which is of the order of the average thickness of the units G1, G2, G3, G4, and G5.

\section{METHODOLOGY}

The approximation method of ray parameter (Walden, 1991) which worked well for angles less than $50^{\circ}$ in the area of interest, transformed the CDP gathers to the angle domain for next calculate the intercept and gradient volumes. Figure 2 corresponds to the INLINE 43 of the seismic cube, where the intercept, in Figure $2 \mathrm{~A}$, exhibits a remarkable lateral continuity. The gradient (Fig. 2B) evidences a lateral discontinuity more significant than that of the intercept.

The density, sonic and dipolar logs $\rho, V_{p}, V_{s}$, along with the interval corresponding to the units G2 to G5 and the upper section of the Ubaque Formation, are the inputs to calculate the $\mathrm{EEI}$ by varying the angle $\chi$ from $-90^{\circ}$ to $90^{\circ}$, according to Eq. (5). The resulting EEl spectrum deployed in Figure $2 \mathrm{C}$ points out a higher variation in the range $-30^{\circ}<\chi<60^{\circ}$. On the other hand, the petrophysical and well-log analysis indicate the following lithology discriminators: shale volume $V_{s h}$, density $\rho$, gamma rays $\gamma$, effective porosity $\emptyset$, Poisson ratio $\sigma, V_{p} / V_{s}$ ratio, Poisson impedance $I P$, Lambda-Rho $\lambda \rho$, Mu-Rho $\mu \rho$, shear modulus $\mu$, shear impedance $I S$, Young $E$, and Bulk $\kappa$ moduli. And the next to discriminate fluids: water saturation $S_{w}$, resistivity $R$, Poisson's ratio $\sigma, V_{p} / V_{s}$ ratio, Poisson impedance IP (Quakenbush et al., 2006), Lambda-Rho $\lambda \rho$, Lambda $\lambda$ and Bulk $\kappa$ moduli.

Equation (5) with well-logs data along the interval G2 Ubaque, generates the pseudo-logs of all above chosen parameters. Their correlation with the EEl logs, included in the spectrum of Figure $2 \mathrm{C}$, locates the optimum angles where the correlation coefficient is maximum. Correlation curves with similar trends conform seven groups that Figure 3 shows, indicating the parameter discriminator of lithology or fluid, its correlation coefficient, and the optimum angle. Table 1 quantifies the maximum correlation coefficients and the optimum angle associated with each parameter. The next step is to select the curves with the highest correlation coefficients of each group and to construct their pseudo-logs at the optimal angles. Figure 4 shows the log of each parameter estimated with well-log together with the calculated EEl pseudo-logs, where the significant similarity in each pair of curves is notorious. Due to the absence of dipolar records in the area, a theoretical $V_{p} / V_{s}$ relation provided the $V_{s} \log$. As a result, the curves of clay volume and porosity looks little similar with a low correlation coefficient, especially in the Gachetá G1 unit. The comparison of the pseudo-log parameter estimated with well-logs against the other one calculated by the EEI measures the reliability to discriminate elastic parameters. The result, in Figure 4, shows the encouraging match between EEI pseudo-log (blue line) and the pseudo-log parameter (red line) which guarantee the confidence in the prediction. However, there is an appreciable mismatch of both clay and porosity curves of tracks 2 and 3 , in the G1 unit, which owns the lowest shale volume. This mismatch is related to the calculus of shear wave velocity from a theoretical relationship with acoustic wave velocity due to the absence of dipolar log along G1 unit.

Table 1 - Curves with their maximum correlation coefficients and its associated angle, and the optimum angle.

\begin{tabular}{|c|c|c|c|}
\hline Curve & Max.Corr. & $\chi_{\max C o r r}$ & $\chi_{\text {optimo }}$ \\
\hline$G R$ & 0.604 & $35^{\circ}$ & \multirow{2}{*}{$32^{\circ}$} \\
\hline$V_{\text {clay }}$ & 0.612 & $32^{\circ}$ & \\
\hline$S_{w}$ & -0.297 & $22^{\circ}$ & \multirow{3}{*}{$25^{\circ}$} \\
\hline Res & -0.083 & $21^{\circ}$ & \\
\hline$\phi$ & -0.600 & $25^{\circ}$ & \\
\hline$\lambda$ & 0.964 & $17^{\circ}$ & \multirow{2}{*}{$17^{\circ}$} \\
\hline$\lambda \rho$ & 0.968 & $17^{\circ}$ & \\
\hline$\mu$ & 0.997 & $-59^{\circ}$ & \multirow{4}{*}{$-46^{\circ}$} \\
\hline$\mu \rho$ & 0.999 & $-46^{\circ}$ & \\
\hline$I S$ & 0.999 & $-42^{\circ}$ & \\
\hline$E$ & 0.996 & $-45^{\circ}$ & \\
\hline$\kappa$ & 0.981 & $10^{\circ}$ & $10^{\circ}$ \\
\hline$\nu$ & 0.949 & $36^{\circ}$ & \multirow{2}{*}{$41^{\circ}$} \\
\hline$v_{p} / v_{s}$ & 0.999 & $41^{\circ}$ & \\
\hline$\rho$ & 0.691 & $19^{\circ}$ & \multirow{2}{*}{$21^{\circ}$} \\
\hline$I P$ & 0.988 & $21^{\circ}$ & \\
\hline
\end{tabular}

\section{INVERSION EEI}

EEl inversion generates reflectivity volumes for each of the following parameters $V_{s h} \phi, \lambda \rho, \mu \rho, \mu, \kappa, V_{p} / V_{s}$ and $I P$ according to their respective angles of $32^{\circ}, 25^{\circ}, 17^{\circ},-46^{\circ}, 10^{\circ}, 41^{\circ}$ and 


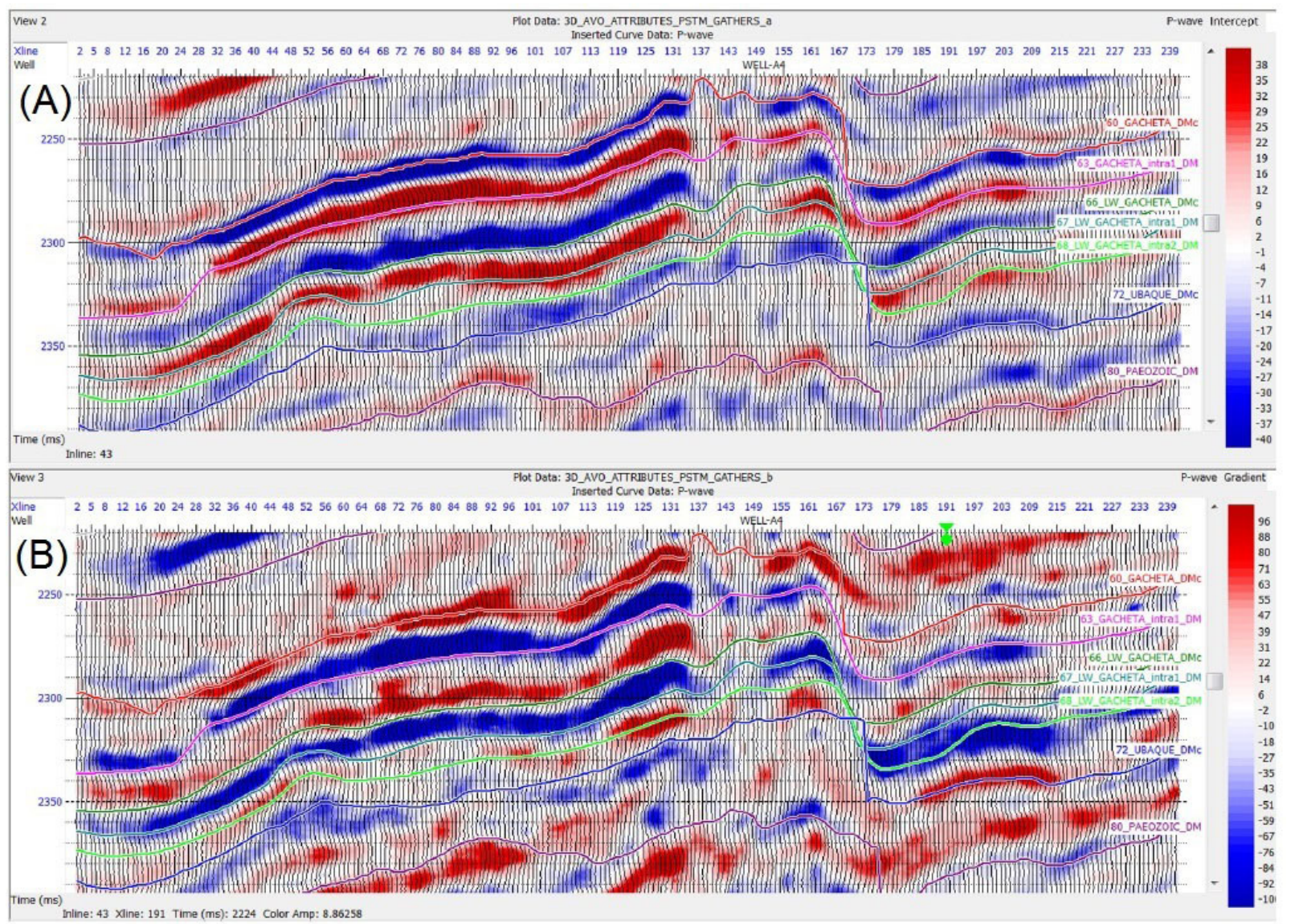

Figure 2(A,B) - AVO analysis of INLINE 111 restricted to the Gachetá G2 interval of the Ubaque Formation provides: A) Seismic section of intercept A; B) Seismic image of gradient $B$.

$21^{\circ}$. With the volumes of intercept $\mathrm{A}$ and gradient $\mathrm{B}$, the expression $R_{E E I}(\chi)=A+B \cdot \tan (\chi)$ generates each parameter cube according to each angle, and other procedure extracts the representative wavelet of each cube. Each parameter has an initial model constructed by filtering the low frequencies of the pseudolog parameter estimated in the well; then this smoothed log was extrapolated to the whole seismic volume following a structural control guided by the interpreted horizons. As a result of the inversion of these seven volumes, Figure 5 shows the distribution of the parameters $V_{s h} \phi, \lambda \rho, \mu \rho, \mu, \kappa, V_{p} / V_{s}$ and $I P$ on the seismic section of the INLINE 43. Figure $5 \mathrm{~A}$ with the shale content distribution indicates that the Guadalupe Formation has low clay content homogeneously distributed with good lateral continuity, which means that sands dominated it. On the other hand, the Gachetá G1 unit and the Ubaque Formation show lateral variations in clay content, while in the Gachetá G2 predominates clays at its base and the content of sands increases to the top.
The units G3, G4 and G5, although dominated by clays, contain sand concentrations that correspond to transverse sections of channels identified with ovals in dotted line, crossing from right to left the images. The distribution of the effective porosity $\emptyset$ in Figure $5 \mathrm{~B}$ shows that the best porosities correspond to the Guadalupe and Ubaque formations, although lower in the latter. The lateral continuity of the Guadalupe Formation becomes visible, as shown in the shale volume section. In general, the Gachetá Formation indicates too low levels of porosity. However, the G1 unit contains quite large green sectors and the rest in pale red, showing that although it is low, the porosity is not zero. The Gachetá G3, G4, and G5 units are mostly with almost no porosity. However, average porosities stand out in the sectors enclosed with black line ovals, other ones in white (porosity of 10\%) and even in green which correspond to the cross-sections of the identified sand channels. The mentioned channels are consistent with the volume of clay. However, the two channels to the left in unit G4 enclosed 


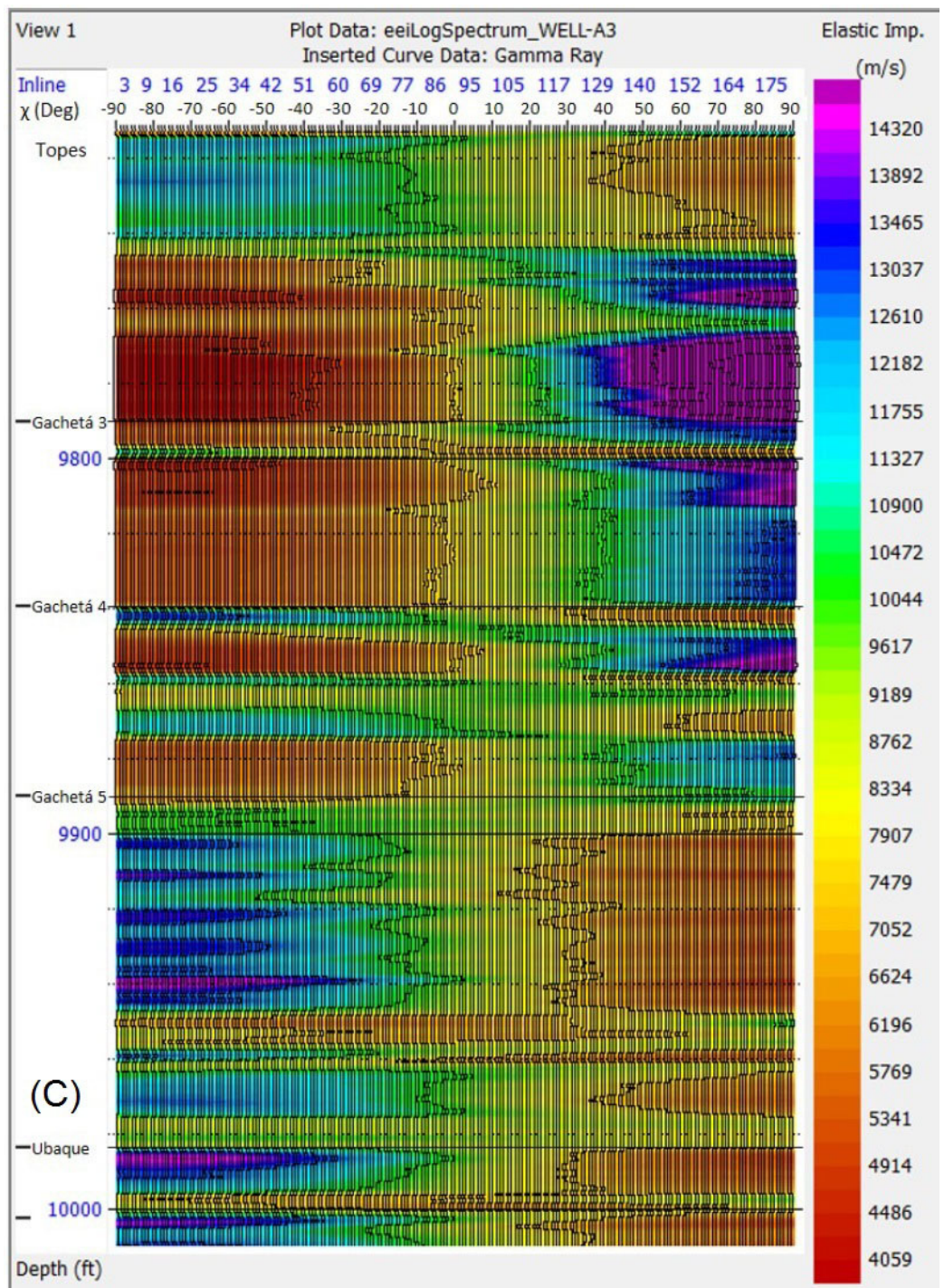

Figure 2(C) - AVO analysis of INLINE 111 restricted to the Gachetá G2 interval of the Ubaque Formation provides: C) Extended Elastic Impedance Spectrum estimated at different angles $\chi$ from $-90^{\circ}$ to $+90^{\circ}$.

in dotted ovals indicate an almost zero porosity due to a higher clay content.

In Figure 5C, $\lambda \rho$ distribution associates low Lambda-Rho values with sands and high ones with clays, showing a remarkable lateral sand continuity in the Ubaque Formation and lower sands quality in the Guadalupe Formation. The units G1 and G3 are sandy while G2, G4, and G5 are clayey, with channels in ovals formerly seen in both porosity and shale volume sections; nevertheless, there are two subtle channels in G3. On the other hand, the $\mu \rho$ distribution in Figure $5 \mathrm{D}$ with little lateral continuity relates low Mu-Rho values with clays and high ones with sands, with a predominance of sands in the Guadalupe and Ubaque for- mations. The units G3, G4, and G5 contain anomalies that coincide with the identified channels. On the contrary, the Bulk modulus distribution in Figure 5 E associates low $\kappa$ values with sands and highs with clays, and where it is noticeable the sandy lateral continuity in the Ubaque Formation and of shale in unit G2. Nevertheless, the sandy Guadalupe Formation that is 100\% saturated with water looks erroneously dominated by clay, due to the Bulk module is sensitive to the presence of fluids. In general, the identified channels coincide with those observed in this section. Contrary to the of $\kappa$ section, the $V_{p} / V_{s}$ distribution in Figure $5 \mathrm{~F}$ has low values for sands and highs ones for clays and points out that both Guadalupe and Ubaque formations are sandy with good 


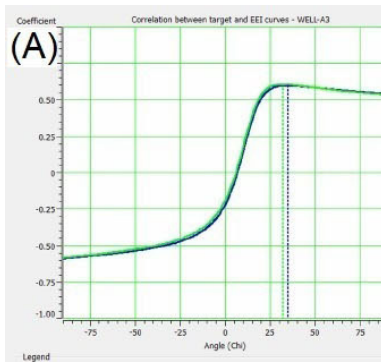

- Gamma ray (max $0.6040 @ 35 \mathrm{deg}$ )

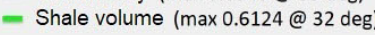

$(\mathrm{E})$

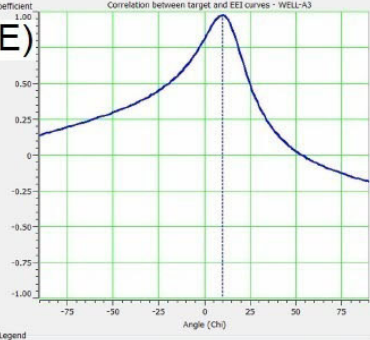

-Compr. modulus (max $0.9808 @ 10 \mathrm{deg}$

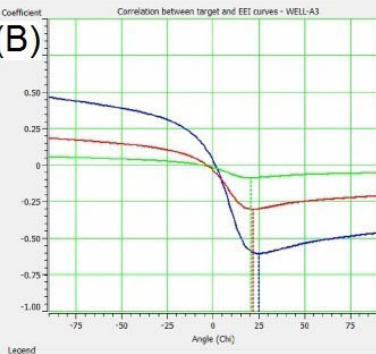

- Porosity (max-0.5996@ 25 deg)

- Resistivity (max-0.0829@ 21 deg) -Water saturation (max-0.2974@22 deg

(C)

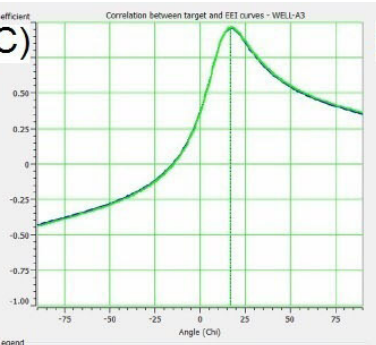

Legens

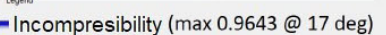

Lambda-Rho (max 0.9679 @ 17 deg)

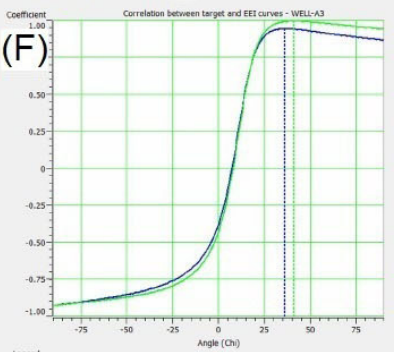

Legend

- Poisson ratio (max $0.9489 @ 36 \mathrm{deg})$

- Vp/Ns ratio (max $0.9995 @ 41 \mathrm{deg})$

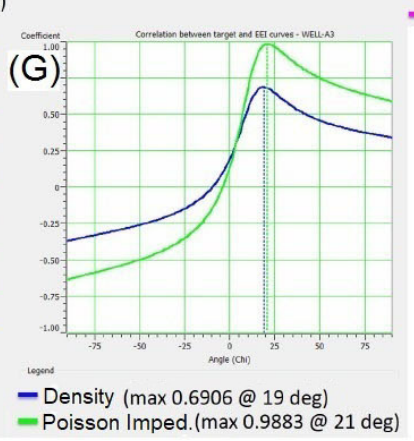

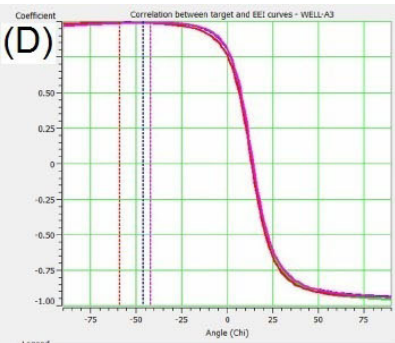

- Mu-Rho(max $0.9993 @-46 \mathrm{deg}$ )

- Shear Imped.(max $0.9992 @-42 \mathrm{deg})$

- Shear modulus(max $0.9974 @-59 \mathrm{deg})$

-Young modulus (max $0.9967 @-42 \mathrm{deg}$ )

Figure 3 - Correlation coefficients between parameter pseudo-logs and EEl spectrum and estimated from - $75^{\circ}$ to $75^{\circ}$. A) Gamma rays $\gamma$ and Shale volume $V_{s h}$. B) Effective Porosity $\emptyset$, Resistivity $R$, and Water saturation $S_{w}$. C) Lambda-Rho $\lambda \rho$ and Lambda $\lambda$. D) Mu-Rho $\mu \rho$, Shear modulus $\mu$, Shear impedance $I S$ and Young modulus $E$. E) Bulk modulus $\kappa$. F) Poisson ratio $\sigma$ and $V_{p} / V_{s}$ ratio; and $\mathrm{G}$ ) Density $\rho$ and Poisson impedance $I P$.

lateral continuity. To the west of the fault, the G1 unit is clayey but contrary to the expected the G2 looks sandy, whereas the same channel anomalies are very remarkable. Finally, the IP distribution deployed in Figure $5 \mathrm{G}$ shows the Guadalupe Formation with low values for sands and highs for clays with a notable lateral continuity, and the Ubaque Formation with high-quality sands while the G1 unit looks with excellent continuity but lower sand quality.

The checking of the reliability of each parameter to discriminate lithology by comparing the pseudo-log parameter and the $R_{E E I}(\chi)$ associated, makes possible to estimate and assign a weight to each $R_{E E I}(\chi)$. These volumes allows the construction of a single one representing the probability that sands dominate each unit. Figure 6 shows the maps at the top of the mentioned units. The division, into units G3, G4, and G5, discriminates the distribution of channels, which as a single unit averages the distribution in the Lower Gachetá, and masks potential reservoirs. The interpretation of G1, G2, and G3 of the Gachetá Formation shows that they lose continuity in the area due to the fault shadow as well as by displacement of around 200 associated to the sinistral component of the fault.

Figure 7 shows the geomorphological interpretation of the transitional environments of the G3, G4 and G5 units and their identified sand channels (yellow lines). The red rectangles in- dicate the areas affected by faults. According to the identification in cores and well-logs that define a transitional environment and according to the interpretation of Figures 7C, 7C and 7D, the Gachetá G3, G4 and G5 units would correspond to a delta estuarine front because of the uniformity of channels and that the sediments between channels present shales of marine characteristics. In the Gachetá G2 unit, the vast content of clays with lateral continuity indicates that its depositional environment ranges from shallow marine to marine, where would be the maximum flooding surface of Cretaceous marine sedimentation. The high content of sand together with the lateral continuity in the Gachetá G1 unit suggests a beach environment, which reflects the beginning of the marine regression of the Late Cretaceous. Figures 7C, 7D, and 7E insinuate a strike displacement of around $200 \mathrm{~m}$ associated to the sinistral strike component of the normal antithetical fault, which interrupted the lateral continuity in the direction and shape of the channels on both sides of the fault.

\section{CONCLUSIONS}

The EEl inversion allows the lithology discrimination of the units of the Cretaceous Gachetá Formation in an onshore seismic project at $3 \mathrm{~km}$ depth and the identification of channels of 


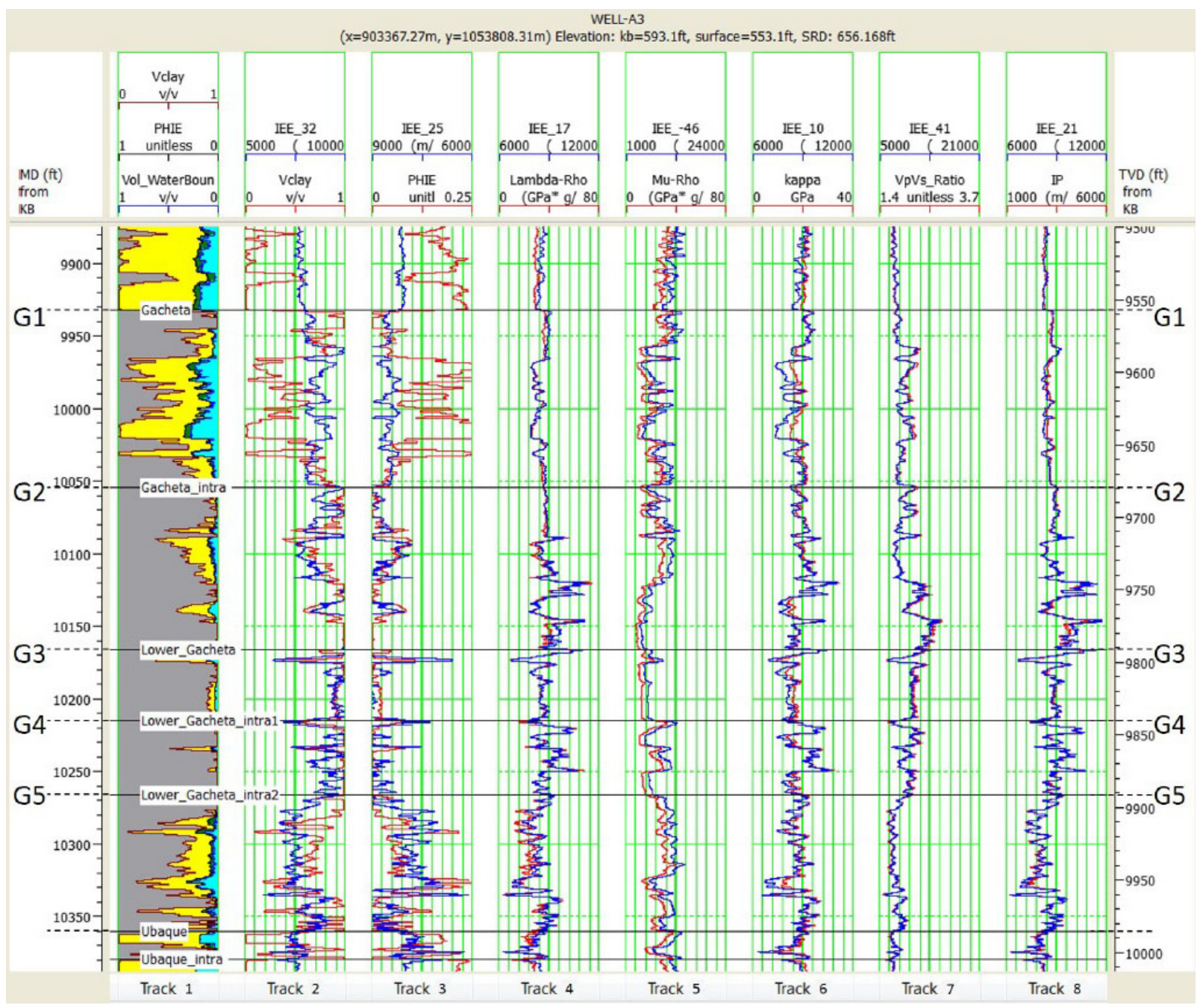

Figure 4 - Comparison between the selected parameters estimated with well-logs (in red) and the respective EEl pseudo-logs at the angles of maximum correlation (in blue). Description of tracks: Track 1 clay content, porosity and water saturation; Track 2 Shale volume and EEl at $32^{\circ}$; Track 3 porosity and EEl at $25^{\circ}$; Track 4 Lambda-Rho and EEl at 17\%; Track $5 \mathrm{Mu}-\mathrm{Rho}$ and EEl at $-46^{\circ}$; Track 6 the Bulk module and EEl at $10^{\circ}$; Track $7 V_{p} / V_{s}$ ration and the EEl at $41^{\circ}$ and Track 8 with Poisson impedance and $\mathrm{EEl}$ at $21^{\circ}$.

transitional environment which are considered potential reservoirs. The results would contribute to both the reduction of exploratory and development risk. The discrimination of sand channels included seven parameters extracted through the EEl inversion, of which the most reliable are the Poisson impedance, the clay volume, the Bulk module and Lambda-Rho; and in a smaller proportion the $V_{p} / V_{s}$ ratio, the porosity, and the MuRho. Two inversions based on different models ran for each parameter, one model generated from the EEl logs and another from well-logs, with self-consistent results. Additionally, the inversion of the EEI logs provides values similar at measured in the well. In the quantitative interpretation of the parameter maps, a lateral discontinuity was noted in direction and shape of the channels at both sides of the fault, which would suggest a displacement of around $200 \mathrm{~m}$ associated with the sinistral strike component of the normal antithetical fault that crosses the seismic volume. Nevertheless, studies of EEl analysis in different wells of the area indicate small differences between the optimal angles for the same parameter, which points out that the coverage of the optimal angle can be limited laterally. Consequently, the results of the studied area should be viewed with caution because the EEI analysis used just the WELL-A3 located in the south-eastern zone of the project area with low seismic coverage, the unique one with an available dipolar log. 


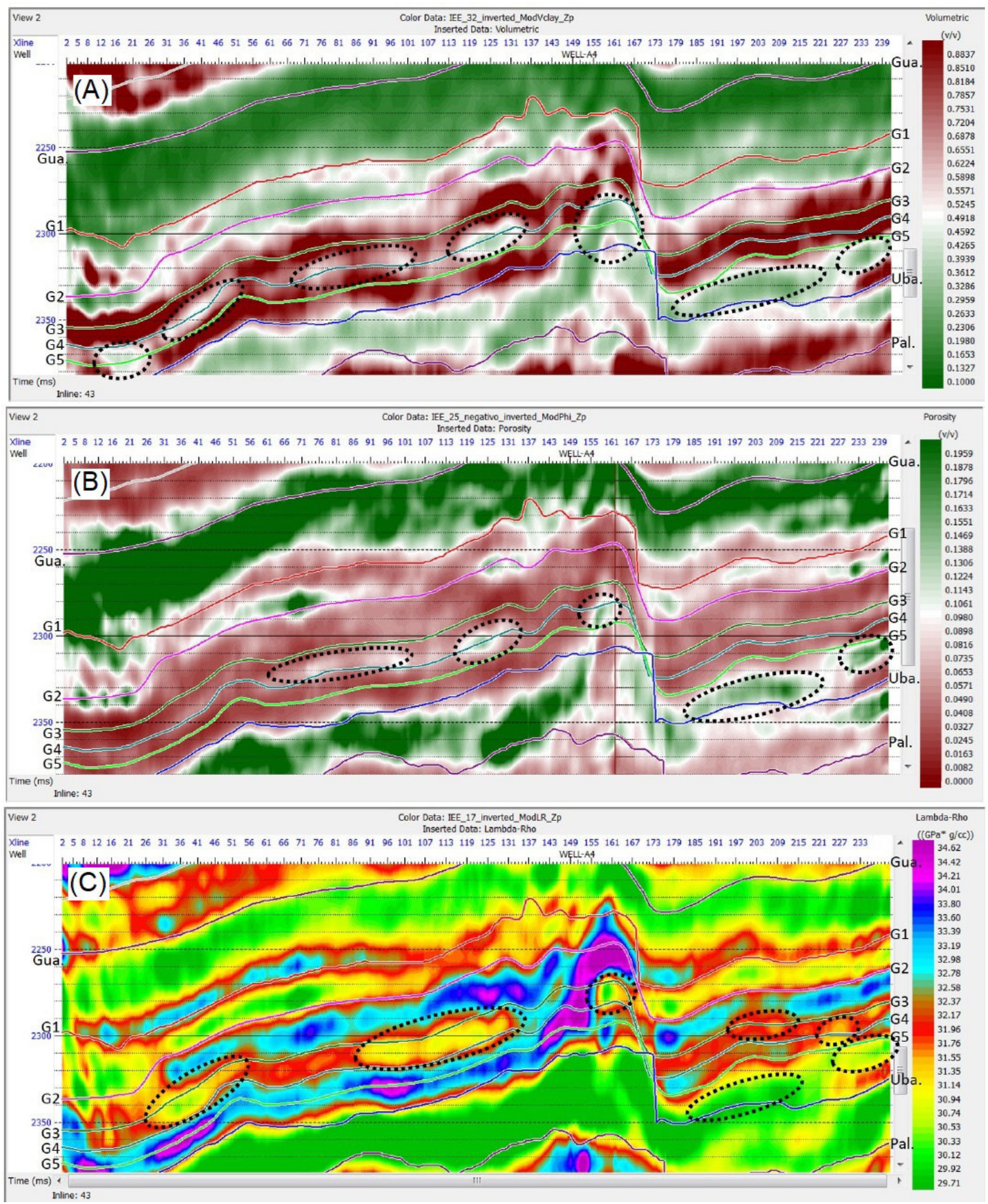

Figure 5(A,B,C) - Sections associated with INLINE 43 of the seismic volume. A) Shale volume estimated as $R_{E E I}\left(32^{\circ}\right)$. B) Porosity estimated as $R_{E E I}\left(25^{\circ}\right)$. C) Lambda-Rho estimated as $R_{E E I}\left(17^{\circ}\right)$. 


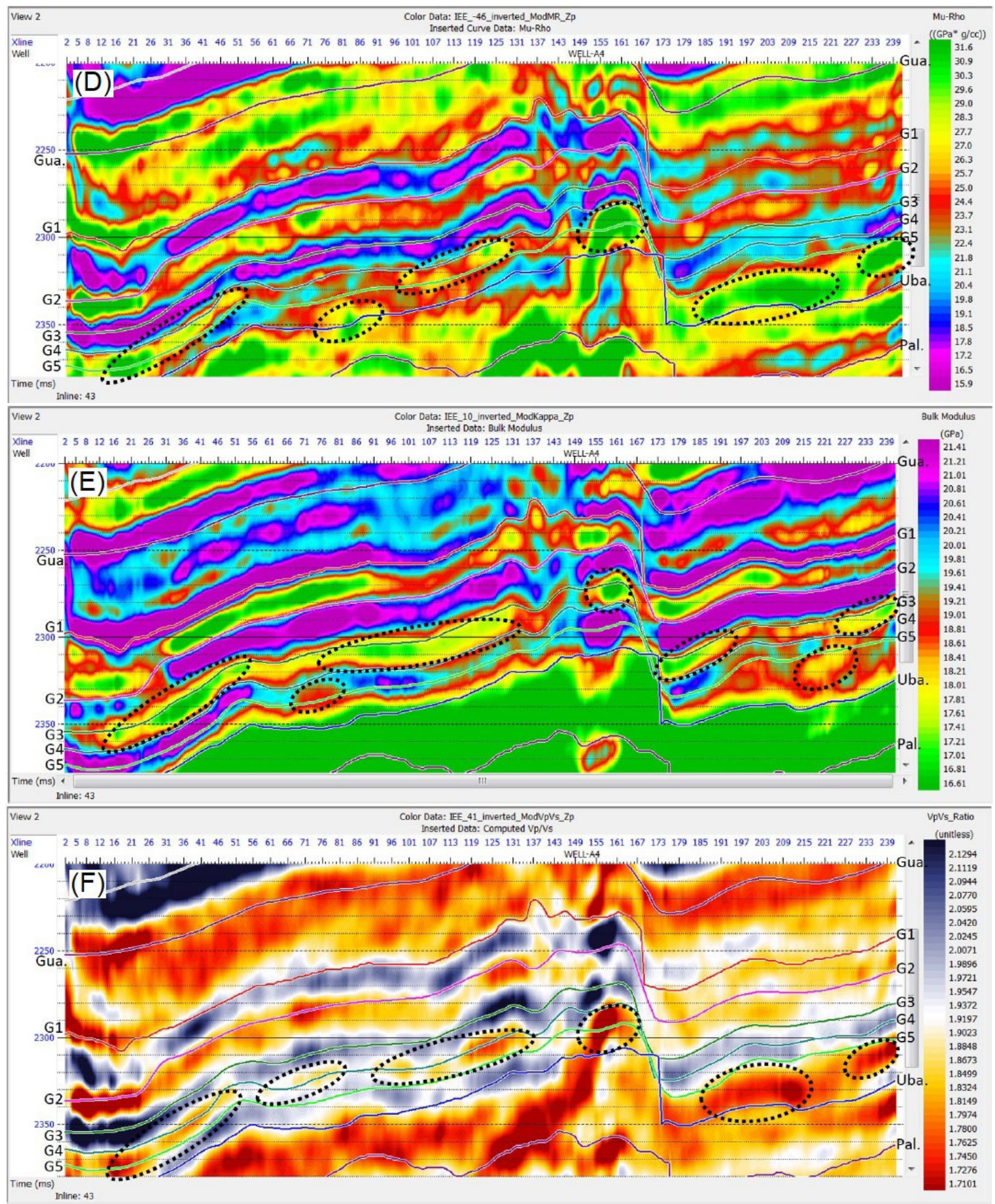

Figure 5(D,E,F) - Sections associated with INLINE 43 of the seismic volume. D) Mu-Rho estimated as $R_{E E I}\left(-46^{\circ}\right)$. E) Bulk module estimated as $R_{E E I}\left(10^{\circ}\right)$. F) $V_{p} / V_{s}$ ratio estimated as $R_{E E I}\left(41^{\circ}\right)$. 


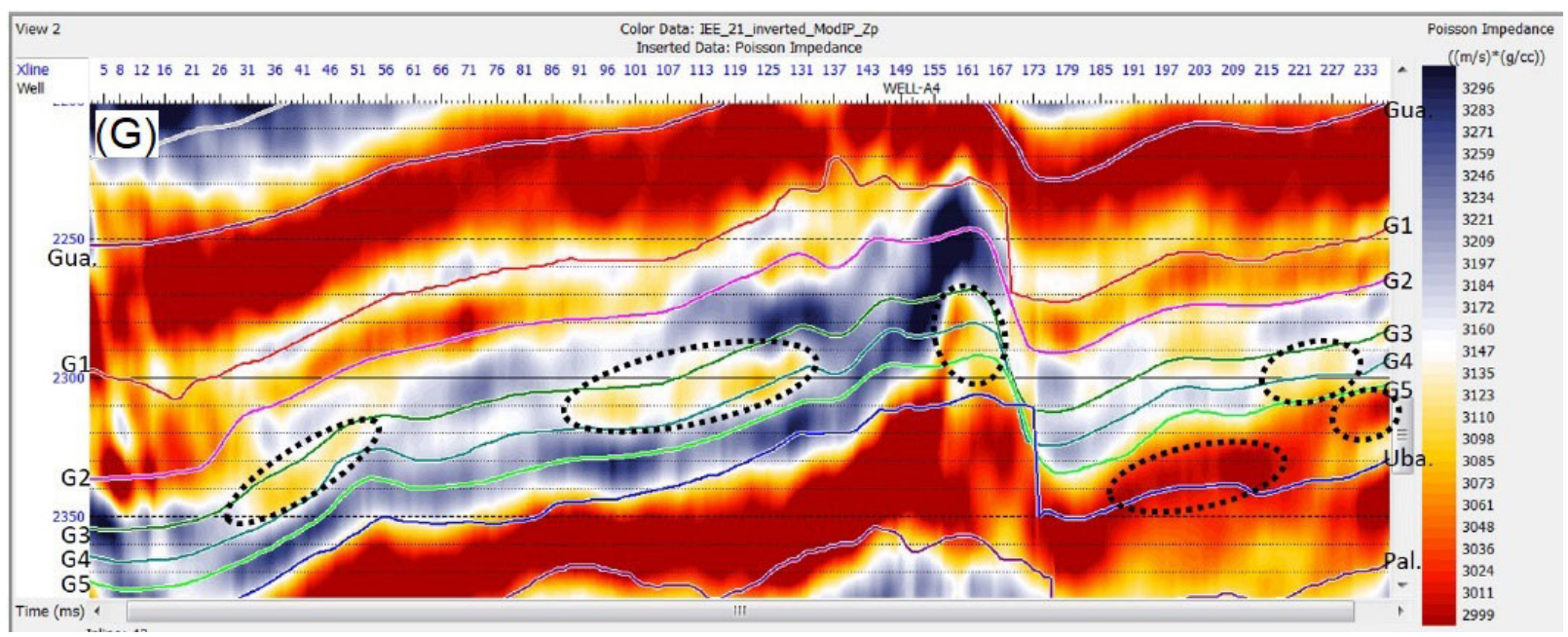

Figure $\mathbf{5 ( G )}$ - Sections associated with INLINE 43 of the seismic volume. G) Poisson impedance estimated as $R_{E E I}\left(21^{\circ}\right)$.

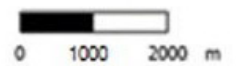

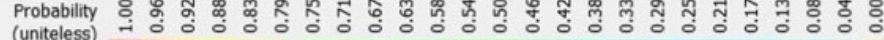
(uniteless)
G1

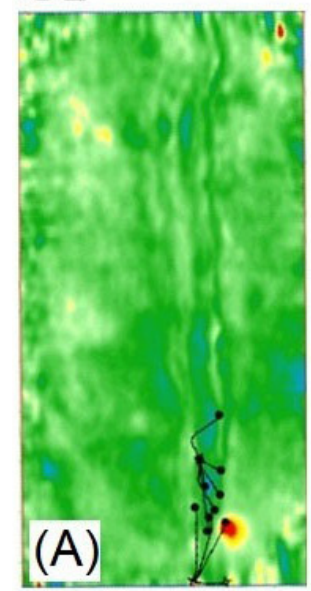

G2

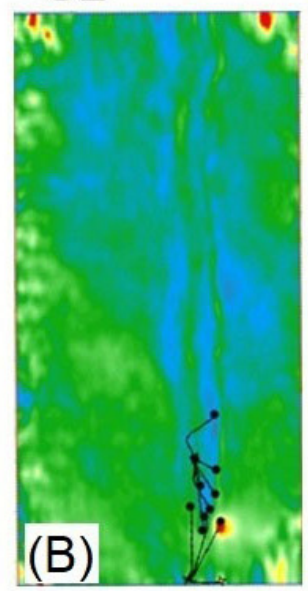

G3

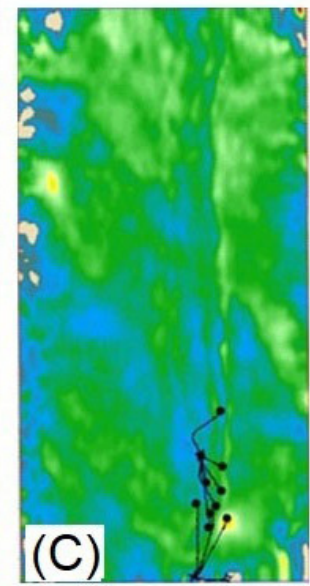

G4

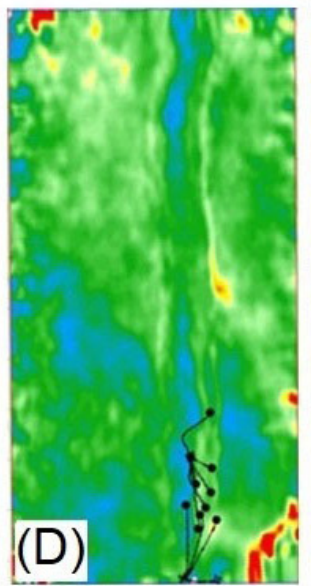

G5

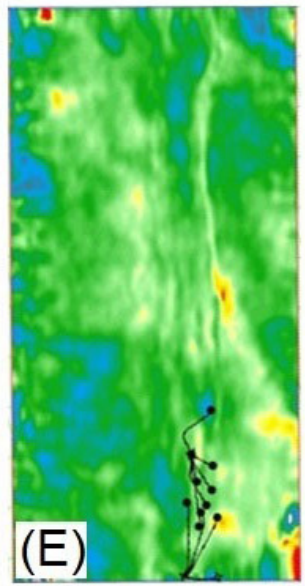

Figure 6 - Maps of probability distribution of sands in following strata: in A) unit G1, in B) unit G2, in C) unit G3, in D) unit G4 and in E) unit G5.

\section{ACKNOWLEDGEMENTS}

The authors thank the Universidad Nacional de Colombia for its support to the research, the Canacol Energy Company for providing the data and the CGG Company for allowing the use of Hampson \& Russell software. Finally, the authors express their recognition to the reviewers by their suggestions and observations to the draft.

\section{REFERENCES}

ARSALAN SI \& YADAV A. 2009. Application of Extended Elastic impedance: A case study from Krishna-Godavari Basin, India. The Lead- ing Edge, 28(10): 1204-1209.

AWOSEMO 0. 2012. Evaluation of elastic impedance attributes in offshore High Island, Gulf of Mexico. Master's thesis, University of Houston, $96 \mathrm{pp}$.

CAMPOS H \& MANN P. 2015. Tectonostratigraphic evolution of the Northern Llanos Foreland Basin of Colombia and implications for its hydrocarbon potential. In: BARTOLINI C \& MANN P (Ed.). Petroleum geology and potential of the Colombian Caribbean Margin. AAPG Memoir, 108: 517-546.

CONNOLLY P. 1999. Elastic impedance. The Leading Edge, 18(4): 438452. 


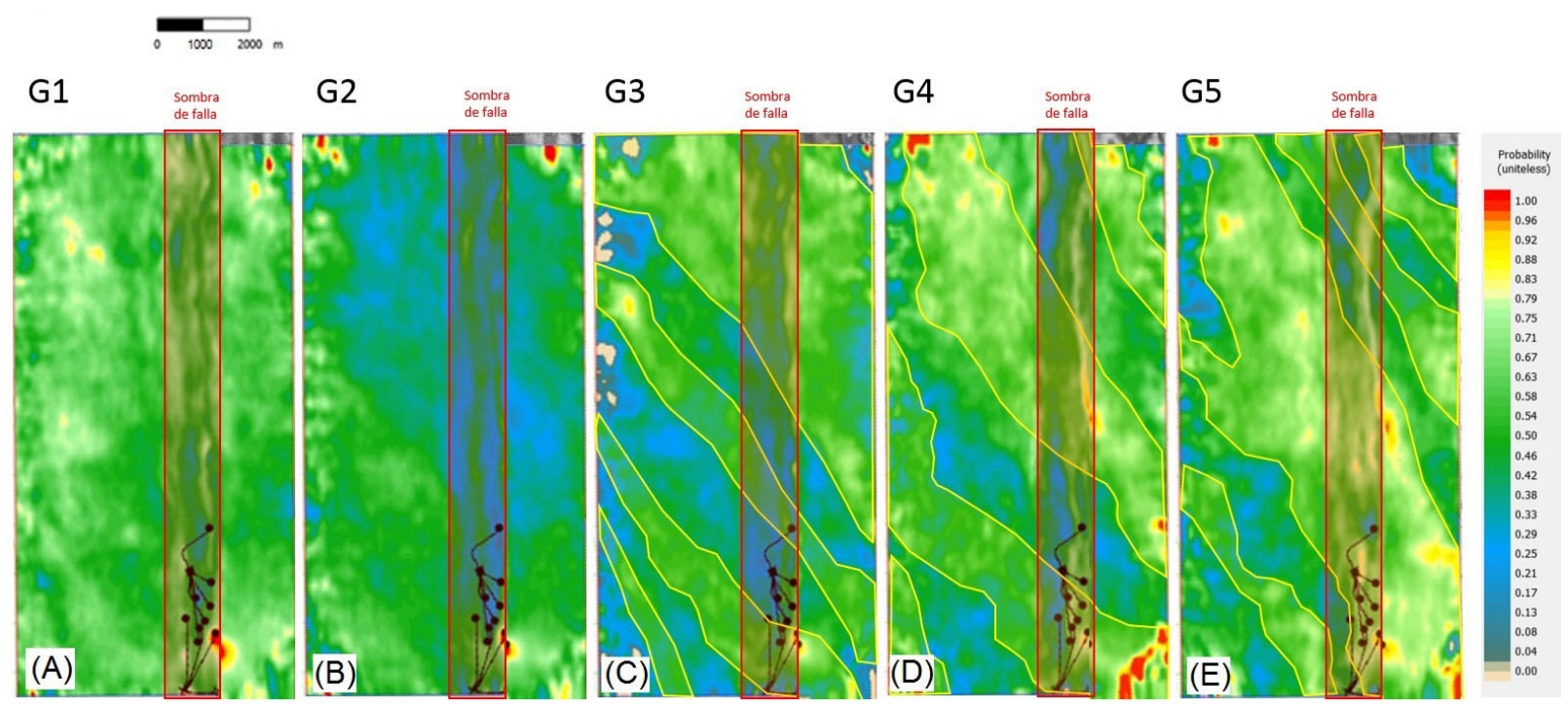

Figure 7 - Probability maps of sand predominance in following layers: in A) unit G1, in B) unit G2, in C) unit G3, in D) unit G4 and in E) unit G5. The channel borders are marked by yellow lines. The areas affected by faults are shown by rectangles suggesting a strike displacement.

CONNOLLY P, SCHURTER GJ \& DAVENPORT M. 2002. Imaging and quantifying turbidites sand systems in deep water Angola using extended elastic impedance. In: Offshore Technology Conference, 6-9 May, Houston, Texas.

DONG W. 1996. A sensitive combination of AVO slope and intercept for hydrocarbon indication. In: 58th EAGE Conference, Amsterdam, The Netherlands, Extended Abstracts, M044.

GOODWAY B, CHEN T \& DOWNTON J. 1997. Improved AVO fluid detection and lithology discrimination using Lamé petrophysical parameters; " $\lambda \rho$ ", " $\mu \rho$ ", \& " $\lambda / \mu$ " fluid stack, from $p$ and $s$ inversions. In: SEG Technical Program Expanded Abstracts, pp. 183-186.

HICKS G \& FRANCIS A. 2006. Porosity and shale volume estimation for the Ardmore field using extended elastic impedance. In: EAGE 68th Conference \& Exhibition - Vienna, Austria. A03.
QUAKENBUSH M, SHANG B \& TUTTLE C. 2006. Poisson impedance. The Leading Edge, 25(2): 128-138.

SHUEYR. 1985. A simplification of the Zoeppritzequations. Geophysics, 50(4): 609-614.

SMITH G \& GIDLOW P. 1987. Weighted stacking for rock property estimation and detection of gas. Geophysical Prospecting, 35: 993-1014.

WALDEN AT. 1991. Making AV0 sections more robust. Geophysical Prospecting, 39(7): 915-942.

WHITCOMBE D. 2002. Elastic impedance normalization. Geophysics, 67(1): 60-62.

WHITCOMBE D, CONNOLLY P, RAEGAN R \& REDSHAW T. 2002. EXtended elastic impedance for fluid and lithology prediction. Geophysics, 67(1): 63-67. 